\title{
A 77-year-old man with nonvariceal upper gastrointestinal bleeding
}

Kyle J. Fortinsky MD, Nathan M. Stall MD, Alan N. Barkun MD CM MSc

1 77-year-old man presents to the emergency department with a one-day history of four melena stools. His medical history includes coronary artery bypass graft surgery, paroxysmal atrial fibrillation and hypertension. His medications include warfarin, ramipril and atorvastatin. On examination, his temperature and oxygen saturation (room air) are normal; his respiratory rate is 18 breaths per minute. In a supine position, his blood pressure is $118 / 68 \mathrm{~mm} \mathrm{Hg}$ with a regular heart rate ( 86 beats/min). After sitting with his legs hanging over the side of the bed for two minutes, his blood pressure is $112 / 64 \mathrm{~mm} \mathrm{Hg}$ and his heart rate is 90 beats/min. Initial laboratory investigations show a hemoglobin level of 66 (normal 140-174) g/L, platelet count of 185 (normal $130-400) \times 10^{9} / \mathrm{L}$, international normalized ratio (INR) of 2.2 (normal 0.9-1.2) and urea level of 3.0 (normal 2.5-8.0) $\mathrm{mmol} / \mathrm{L}$. His electrocardiogram shows a normal sinus rhythm with no evidence of ischemia.

\section{What are the immediate steps to stabilize this patient?}

The immediate priority is to secure the patient's circulation. The patient should be placed in a monitored area, and blood collected for typing and cross-matching. ${ }^{1}$ Venous access should be established with two large-bore intravenous catheters, and volume resuscitation initiated with crystalloid fluids. ${ }^{1}$ It is important to recognize a suspected variceal bleed because this may necessitate a different management strategy. Several bedside variables are associated with an increased likelihood of a variceal source of upper gastrointestinal bleeding: history of liver disease (odds ratio [OR] 6.7), excessive alcohol use (OR 2.3), hematemesis (OR 2.7), hematochezia (OR 3.0), and stigmata of chronic liver disease (OR 2.5). ${ }^{2}$

\section{Does he require admission to hospital and urgent endoscopy?}

Limited observational data suggest that therapeutic endoscopy appears to be safe for patients with an INR less than 2.5. ${ }^{3}$ The risk of upper gastrointestinal bleeding should be stratified for all patients with presumed bleeding using a validated scale. ${ }^{4}$ Although several exist, the Glasgow-Blatchford bleeding score (Box 1) has been prospectively validated. A multicentre prospective trial involving 676 patients found that only patients with a Glasgow-Blatchford bleeding score of zero can be safely discharged home. ${ }^{5}$ All other patients who present with presumed upper gastrointestinal bleeding require admission to hospital and endoscopy. Emerging observational evidence suggests that patients with Glasgow-Blatchford scores of 12 or higher may benefit from endoscopy within 13 hours ${ }^{6}$ however, Canadian guidelines maintain that all patients should receive endoscopy within 24 hours of presentation. ${ }^{4}$

\section{Should he be given a packed red blood cell transfusion?}

A recent randomized controlled trial involving 921 patients with acute upper gastrointestinal bleeding found that a restrictive transfusion strategy (target hemoglobin $>70 \mathrm{mmol} / \mathrm{L}$ ) decreased six-week mortality, length of stay and transfusion-related adverse events compared with a liberal transfusion strategy (target hemoglobin $>90$ $\mathrm{mmol} / \mathrm{L}){ }^{7}$ The overall mortality benefit conferred by the restrictive strategy was driven primarily by patients with Child-Pugh class A or B cirrhosis. There was no significant mortality benefit of the restrictive strategy among patients with Child-Pugh class $\mathrm{C}$ cirrhosis or with bleeding from a peptic ulcer, although trends in improvement were noted. This study did not examine the effect of the two transfusion strate-
Competing interests:

Nathan Stall is a freelance news writer for and serves on the editorial advisory board of CMAJ. Alan Barkun has received speakers fees from AstraZeneca and Takeda, has served as a consultant for Olympus, Takeda

Canada and Pendopharm Canada. He has received research support from Boston Scientific and Cook Inc. No other competing interests declared.

This article has been peer reviewed.

Correspondence to: Nathan Stall, nathan.stall@mail.utoronto .ca

CMAJ 2014. DOI:10.1503 /cmaj.131288 
gies among patients with pre-existing cardiovascular disease or severe hemorrhagic shock, despite consensus guidelines suggesting higher hemoglobin targets for these patients. ${ }^{4}$

\section{Does he require correction of coagulopathy or transfusion of platelets?}

Expert consensus recommends reversing coagulopathy in patients receiving anticoagulants, but this should not delay endoscopy unless the INR is supratherapeutic. A systematic review of 18 studies examining platelet transfusion thresholds in patients with acute upper gastrointestinal bleeding concluded that there is insufficient evidence to recommend an optimal platelet count. ${ }^{8}$ Based primarily on expert opinion, a platelet transfusion threshold of $50 \times 10^{9} / \mathrm{L}$ has been proposed. ${ }^{8}$

\section{Should he be started on proton pump inhibitor or prokinetic therapy before endoscopy?}

Although proton pump inhibitor therapy after endoscopy reduces the rate of rebleeding, need

\begin{tabular}{|c|c|}
\hline \multicolumn{2}{|c|}{ Box 1: Glasgow-Blatchford Score ${ }^{4}$} \\
\hline Admission risk marker & $\begin{array}{c}\text { Score } \\
\text { component value }\end{array}$ \\
\hline \multicolumn{2}{|l|}{ Blood urea, $\mathrm{mmol} / \mathrm{L}$} \\
\hline $6.5-7.9$ & 2 \\
\hline $8.0-9.9$ & 3 \\
\hline $10.0-25.0$ & 4 \\
\hline$>25.0$ & 6 \\
\hline \multicolumn{2}{|l|}{ Hemoglobin for men, g/L } \\
\hline $120-129$ & 1 \\
\hline $100-119$ & 3 \\
\hline$<100$ & 6 \\
\hline \multicolumn{2}{|l|}{ Hemoglobin for women, g/L } \\
\hline $100-119$ & 1 \\
\hline$<100$ & 6 \\
\hline \multicolumn{2}{|l|}{ Systolic blood pressure, $\mathrm{mm} \mathrm{Hg}$} \\
\hline $100-109$ & 1 \\
\hline $90-99$ & 2 \\
\hline$<90$ & 3 \\
\hline \multicolumn{2}{|l|}{ Other markers } \\
\hline Pulse $\geq 100 / \mathrm{min}$ & 1 \\
\hline Presentation with melena & 1 \\
\hline Presentation with syncope & 2 \\
\hline Hepatic disease & 2 \\
\hline Cardiac failure & 2 \\
\hline \multicolumn{2}{|c|}{$\begin{array}{l}\text { Reprinted from The Lancet, vol. 365, Blatchford O, Murray } \\
\text { WR, Blatchford M. A risk score to predict the need for } \\
\text { treatment for upper-gastrointestinal haemorrhage. Page } \\
\text { no. 1318-21, 200, with permission from Elsevier. }{ }^{4}\end{array}$} \\
\hline
\end{tabular}

for surgery and mortality for certain patients, ${ }^{9}$ the benefits in pre-endoscopic management are less certain, despite their widespread use. A Cochrane meta-analysis of six randomized controlled trials involving 2223 patients reported that the use of pre-endoscopic proton pump inhibitors reduced the need for endoscopic therapy (OR $0.68,95 \%$ CI $0.50-0.93$ ) but had no effect on mortality, rebleeding or the need for surgery. ${ }^{10}$ No significant difference in any outcome was found between intravenous and oral preparations. Given its favourable safety profile, pre-endoscopic proton pump inhibitor therapy may be considered but should not delay resuscitation or endoscopy. ${ }^{4}$ Prokinetic agents such as erythromycin and metoclopramide administered before endoscopy may increase visualization and reduce the need for repeat endoscopy. ${ }^{11}$ The routine use of these agents is controversial and is not supported by current international guidelines. ${ }^{4}$

\section{The case revisited}

The patient was placed in a monitored area, and venous access was established with two 16gauge intravenous catheters. Because he had no features suggestive of a variceal source of bleeding, he was thought to have a nonvariceal upper gastrointestinal bleed. He was admitted to hospital because his Glasgow-Blatchford score was seven (Box 1). One unit of packed red blood cells was transfused, and his hemoglobin level four hours later was $75 \mathrm{~g} / \mathrm{L}$. Proton-pump inhibitor therapy was initiated, along with vitamin $\mathrm{K}$ for reversal of anticoagulation. The patient was admitted to the internal medicine ward, and the gastroenterology service was consulted. Endoscopy was performed within 24 hours of presentation and showed a single duodenal ulcer with a clean base; no intervention was required. Biopsies were taken to rule out Helicobacter pylori infection, and the patient was discharged home with pantoprazole taken orally once daily.

The clinician and patient discussed the benefits and risks of reintroducing warfarin after upper gastrointestinal bleeding. ${ }^{12}$ A recent retrospective cohort study involving 442 patients found that patients who resumed warfarin therapy within 90 days of upper gastrointestinal bleeding (median resumption of $4 \mathrm{~d}$ ) had decreased overall mortality and thrombosis without an increased risk of recurrent gastrointestinal bleeding. ${ }^{13}$ Considering this limited evidence and the low-risk findings on endoscopy, the patient was comfortable restarting warfarin four days later. Follow-up was arranged with the patient's family physician to repeat a complete blood count, 
monitor warfarin therapy, and discuss the biopsy results for Helicobacter pylori.

\section{References}

1. Laine L, Jensen DM. Management of patients with ulcer bleeding Am J Gastroenterol 2012;107:345-60.

2. Alharbi A, Almadi M, Barkun A, et. al., REASON Investigators Predictors of a variceal source among patients presenting with upper gastrointestinal bleeding. Can J Gastroenterol 2012;26: 187-92.

3. Choudari CP, Rajgopal C, Palmer KR. Acute gastrointestinal haemorrhage in anticoagulated patients: diagnoses and response to endoscopic treatment. Gut 1994;35:464-6.

4. Barkun AN, Bardou M, Kuipers EJ, et al. International consensus recommendations on the management of patients with nonvariceal upper gastrointestinal bleeding. Ann Intern Med 2010; 152:101-13.

5. Blatchford O, Murray WR, Blatchford M. A risk score to predict the need for treatment for upper-gastrointestinal haemorrhage. Lancet 2000;356:1318-21.

6. Lim LG, Ho KY, Chan YH, et al. Urgent endoscopy is associated with lower mortality in high-risk but not low-risk nonvariceal upper gastrointestinal bleeding. Endoscopy 2011;43:300-6.

7. Villanueva C, Colomo A, Bosch A, et al. Transfusion strategies for acute upper gastrointestinal bleeding. N Engl J Med 2013; 368:11-21.

8. Razzaghi A, Barkun AN. Platelet transfusion threshold in patients with upper gastrointestinal bleeding: a systematic review. J Clin Gastroenterol 2012;46:482-6.

9. Leontiadis GI, Sharma VK, Howden CW. Proton pump inhibitor therapy for peptic ulcer bleeding: Cochrane collaboration metaanalysis of randomized controlled trials. Mayo Clin Proc 2007; 82:286-96.

10. Sreedharan A, Martin J, Leontiadis GI, et al. Proton pump inhibitor treatment initiated prior to endoscopic diagnosis in upper gastrointestinal bleeding. Cochrane Database Syst Rev 2010;(7):CD005415.

11. Barkun AN, Bardou M, Martel M, et al. Prokinetics in acute upper GI bleeding: a meta-analysis. Gastrointest Endosc 2010; 72:1138-45.

12. Almadi MA, Barkun A, Brophy J. Antiplatelet and anticoagulant therapy in patients with gastrointestinal bleeding: an 86-year-old woman with peptic ulcer disease. JAMA 2011;306:2367-74.

13. Witt DM, Delate T, Garcia DA, et al. Risk of thromboembolism, recurrent hemorrhage, and death after warfarin therapy interruption for gastrointestinal tract bleeding. Arch Intern Med 2012;172:1484-91.

Affiliations: Department of Medicine (Fortinsky, Stall) University of Toronto, Toronto, Ont.; Gastroenterology and Clinical Epidemiology (Barkun), McGill University, Montréal, Que.

Contributors: All of the authors contributed to the conceptualization of the manuscript. Kyle Fortinsky and Nathan Stall drafted the manuscript, which all authors revised. All authors approved the final version submitted for publication.

Decisions is a series that focuses on practical evidence-based approaches to common presentations in primary care. The articles address key decisions that a clinician may encounter during initial assessment. The information presented can usually be covered in a typical primary care appointment. Articles should be no longer than 650 words, may include one box, figure or table and should begin with a very brief description ( 75 words or less) of the clinical situation. The decisions addressed should be presented in the form of questions. A box providing helpful resources for the patient or physician is encouraged.

\section{Change of address}

We require 6 to 8 weeks' notice to ensure uninterrupted service. Please send your current mailing label, new address and the effective date of change to:

\section{CMA Member Service Centre}

1870 Alta Vista Dr., Ottawa ON K1G 6R7

tel $888855-2555$ or $613731-8610 \times 2307$

fax $613236-8864$

cmamsc@cma.ca

\section{Changement d'adresse}

II nous faut de 6 à 8 semaines d'avis afin de vous assurer une livraison ininterrompue. Veuillez faire parvenir votre étiquette d'adresse actuelle, votre nouvelle adresse et la date de la prise d'effet du changement, à l'attention du

Centre des services aux membres de l'AMC 1870, prom. Alta Vista, Ottawa ON K1G 6R7

tél 888 855-2555 ou $613731-8610$ x2307 fax 613 236-8864

cmamsc@cma.ca

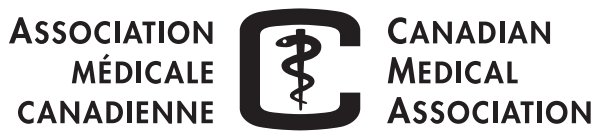

